Special issue of the 2nd International Conference on Computational and Experimental Science and Engineering (ICCESEN 2015)

\title{
Neutron-Induced Medical Radioisotope Production in a Conceptual Accelerator-Driven System, Fueled with Uranium Carbide
}

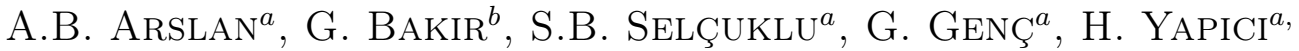 \\ ${ }^{a}$ Erciyes Üniversitesi, Enerji Sistemleri Mühendisliği Bölümü, Kayseri, Turkey, \\ ${ }^{b}$ Cumhuriyet Üniversitesi, Enerji Sistemleri Mühendisliği Anabilimdalı, Sivas, Turkey
}

\begin{abstract}
In this study, the medical radioisotope production performance of a conceptual accelerator-driven system is investigated. Lead-bismuth eutectic is used as target material. The fuel core of the considered accelerator-driven system is divided into ten subzones, loaded with uranium carbide and various isotopes (isotopes of copper, gold, cobalt, holmium, rhenium, scandium, and thulium) and cooled with light water. As is known, light water is an effective moderator of neutrons as well as a good coolant. The fuel and the isotopes are separately placed as cylindrical rods with a cladding of carbon composite. The volume fractions of fuel, isotope, cladding and coolant are selected as $25 \%, 35 \%, 10 \%$ and $30 \%$, respectively. The copper rods are placed into the first five subzones due to the fact that copper isotopes have low capture cross-section. In the case of the each radioisotope production, one of the other considered isotopes that have higher capture cross-section are placed into the following five subzones for optimization of fission, fissile breeding and radioisotope production. The graphite zone is located around the fuel core to reflect the escaping neutrons. Boron carbide $\left(\mathrm{B}_{4} \mathrm{C}\right)$ is used as shielding material. In order to produce more neutrons (about 25-30 neutrons per $1 \mathrm{GeV}$ proton), the target is irradiated with a continuous beam of $1 \mathrm{GeV}$ protons. All neutronic computations have been performed with the high-energy Monte Carlo N-Particle Transport Code using the LA150 data library. The neutronic results obtained from these calculations show that the examined accelerator-driven system has a high neutronic capability, in terms of production of thermal power, fissile fuels, and medical radioisotopes.
\end{abstract}

DOI: 10.12693/APhysPolA.130.68

PACS/topics: 28.20.-v, 28.20.Np, 28.65.+a, 29.85.Fj, 29.20.-c

\section{Introduction}

In medicine applications, many radioisotopes are used for the treatment and diagnosis of illnesses. Therefore, many researchers focus their attention on medical radioisotope production. These radioisotopes are produced by neutron capture reaction in nuclear reactors. Currently, new radioisotope production as well as nuclear waste transmutation is an available method in accelerator-driven systems (ADSs) based on a proton source.

An ADS has three main regions, namely; (a) proton accelerator, (b) spallation neutron target (SNT), and (c) subcritical core. In order to release a few tens of high energy neutrons, energetic proton particles coming from the accelerator bombard the SNT. These neutrons diffuse through the subcritical core to produce high energy by fission reaction and to transmute nuclear isotopes.

Recently, in nuclear medicine, many studies on generation of medical radioisotopes by nuclear transmutation have been performed in various nuclear reactors. Starovoitova, et al. [1] have worked on medical radioisotope production in linear accelerators by means of photoneutron and photoproton reactions. The simulation results of their study show that activities of $99 \mathrm{Mo}$ and $67 \mathrm{Cu}$ are about $7 \mathrm{MBq} /(\mathrm{gkWh})$ and about $1 \mathrm{MBq} /(\mathrm{g} \mathrm{kWh})$,

corresponding author; e-mail: yapici@erciyes.edu.tr respectively. Richards, et al. [2] have investigated the production of ${ }^{99 \mathrm{~m}} \mathrm{Tc}$ from $100 \mathrm{Mo} 2 \mathrm{C}$ targets by $(\mathrm{p}, 2 \mathrm{n})$ reactions in a medical cyclotron accelerator. Webster, et al. [3] have studied the production of three medically important radionuclides, $89 \mathrm{Y}(\mathrm{p}, \mathrm{n}) 89 \mathrm{Zr}, 64 \mathrm{Ni}(\mathrm{p}, \mathrm{n}) 64 \mathrm{Cu}$ and $103 \mathrm{Rh}(\mathrm{p}, \mathrm{n}) 103 \mathrm{Pd}$ reactions in a compact and lowenergy accelerator system. They claim that the considered accelerator system has sufficient production quantities of $89 \mathrm{Zr}, 64 \mathrm{Cu}$, and $103 \mathrm{Pd}$ for the medical applications. They also suggest that this system can be used for production of many other medical isotopes. An accelerator driven neutron activator, based on a modified version of the adiabatic resonance crossing (ARC) concept has been developed for medical radioisotope production by Abbas, et al. [4]. They have investigated pure Au, Mo, Ho, and Re foils as well as Re and Ho nanoparticle samples, and obtained higher production yields of 99Mo and $198 \mathrm{gAu}$ with respect to literature. Kin, et al. [5] have studied new production routes for copper isotopes $(64 \mathrm{Zn}(\mathrm{n}, \mathrm{p}) 64 \mathrm{Cu}, 67 \mathrm{Zn}(\mathrm{n}, \mathrm{p}) 67 \mathrm{Cu}, 68 \mathrm{Zn}(\mathrm{n}, \mathrm{x}) 67 \mathrm{Cu})$ by using accelerator neutrons. They have shown that $64 \mathrm{Zn}(\mathrm{n}, \mathrm{p}) 64 \mathrm{Cu}$ reaction has a promising route to produce $64 \mathrm{Cu}$. Tárkányi, et al. [6-9] have investigated production of the therapeutic radioisotopes $165 \mathrm{Er}$ by means of deuteron and proton particle bombardment reactions. Furthermore, production of various radioisotopes in particle accelerators has been examined by many researchers [10-15]. 
In our previous works $[16,17]$, the neutronic data in various infinite target medium, bombarded with a proton source of $1000 \mathrm{MeV}$ have been investigated. The results show that $1000 \mathrm{MeV}$ proton source is optimum for gain $G$, which is one of the important parameters of an ADS. This study presents a conceptual ADS design. The potential of radioisotope productions in a lead-bismuth eutectic (LBE) accelerator driven system is investigated.

\section{Computational model of the considered ADS}

In this work, large-scale radio-isotope breeding in a conceptual accelerator driven subcritical system, loaded with uranium carbide (UC) and cooled with light water is analyzed. The considered ADS is shown in Fig. 1, and the materials used in this ADS are given in Table I.

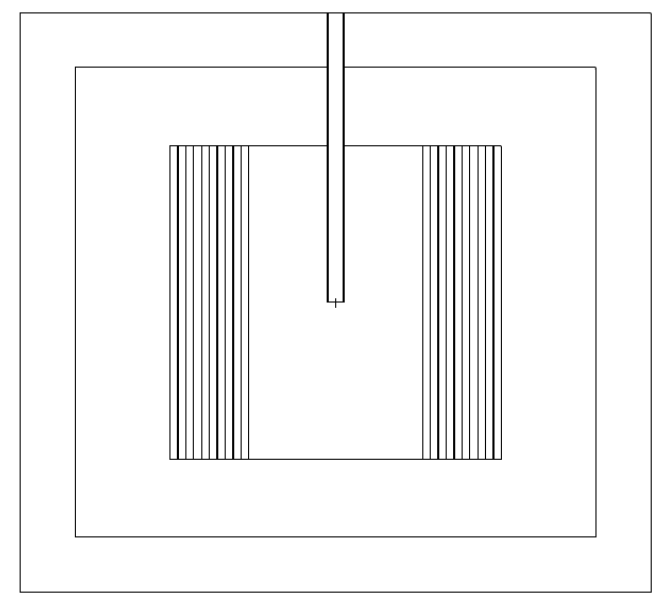

Fig. 1. Cross sectional view of the ADS.

\section{TABLE I}

Isotopic fractions and densities of the materials used in the investigated ADS.

\begin{tabular}{c|c|c|c}
\hline \hline Material & Density $\left[\mathrm{g} / \mathrm{cm}^{3}\right]$ & Nuclide & Fraction [\%] \\
\hline $\mathrm{LBE}$ & 11.3449 .8 & $\mathrm{~Pb}$ & 44.5 \\
$\mathrm{H}_{2} \mathrm{O}$ & 1.0 & $\mathrm{Bi}$ & 55.5 \\
$\mathrm{UC}$ & 13.63 & ${ }^{235} \mathrm{U}$ & $8.2-13.5$ \\
$\mathrm{C} / \mathrm{C}$ & 1.85 & ${ }^{238} \mathrm{U}$ & $91.8-86.5$ \\
$\mathrm{Cu}$ & 8.92 & ${ }^{12} \mathrm{C}$ & 100 \\
& & ${ }^{63} \mathrm{Cu}$ & 68 \\
$\mathrm{Au}$ & 18.88 & ${ }^{197} \mathrm{Au}$ & 32 \\
$\mathrm{Co}$ & 8.9 & ${ }^{59} \mathrm{Co}$ & 100 \\
$\mathrm{Ho}$ & 8.795 & ${ }^{165} \mathrm{Ho}$ & 100 \\
$\mathrm{Re}$ & 20.53 & ${ }^{185} \mathrm{Re}$ & 37 \\
& & ${ }^{187} \mathrm{Re}$ & 63 \\
$\mathrm{Sc}$ & 2.989 & ${ }^{45} \mathrm{Sc}$ & 100 \\
$\mathrm{Tm}$ & 9.321 & ${ }^{169} \mathrm{Tm}$ & 100
\end{tabular}

The ADS consist of four parts, namely, the leadbismuth eutectic (LBE) spallation target, the transmutation zone (TZ), the graphite reflector zone (RZ) and shielding zone made of boron carbide $\left(\mathrm{B}_{4} \mathrm{C}\right)$. The fuel (UC) and isotopes in the shape of cylindrical rods in a cladding of carbon composite $(\mathrm{C} / \mathrm{C})$ are separately placed in the TZ. The isotopes of copper, gold, cobalt, holmium, rhenium, scandium, and thulium are analyzed to breed new radioisotopes that can be often used in medicine for the treatment and diagnosis of illnesses. The TZ is divided into ten subzones. The copper having low capture cross-section is put into the isotope rods in the first five subzones. One of the other considered isotopes having higher capture cross-section with respect to the copper is put into the isotope rods in the next five zones. The volume fractions of fuel, isotope, cladding and coolant are 25\%,35\%,10\% and 30\%, respectively. The uranium enrichment is determined in such way, that the neutron multiplication factor $k_{\text {eff }}=0.98$ is ensured. The effective neutron multiplication factor $\left(k_{\text {eff }}\right)$ is the ratio of number of neutrons in one generation over number of neutrons in the next generation. The uranium enrichment was varied in the range of $8.2-13.5 \%$, depending on type of the isotope. Moreover, in order to return the neutrons back towards to the TZ and to absorb the neutrons escaping from the RZ, the TZ is enclosed within a graphite reflector and boron carbide $\left(\mathrm{B}_{4} \mathrm{C}\right)$ shielding zones.

\section{Numerical results}

The neutronic performance of the considered ADS is analyzed by using Monte Carlo code MCNPX 2.7 [18] and the LA150 library [19]. "The library consists of evaluated reaction cross sections and emission spectra up to $150 \mathrm{MeV}$ for incident neutrons and protons for over 40 target isotopes important in the SNTs, structural materials, and shielding" [17]. For calculation of the spallation reactions, Bertini INC model [20] is selected. The optimum gain $G$ can be obtained in the case of proton energy $E_{\mathrm{p}}=1 \mathrm{GeV}[16-17]$.

\subsection{Fission density and energy gain}

Figure 2 shows the fission densities $\left(\mathrm{R}_{\mathrm{f}} \mathrm{D}\right)$. In all considered cases the profiles of fission density decrease through the core, which is a general characteristic of an ADS. Only the profile of fission density of copper is lower than the other profiles. The other profiles, with the exception of the scandium profile, are similar.

The ratio of the total energy production to the energy of the proton beam is known as the energy gain $G$. It is calculated as follows:

$$
G=\frac{R_{\mathrm{f}} E_{\mathrm{f}}}{E_{\mathrm{p}}},
$$

where $R_{\mathrm{f}}$ is the number of fission reaction and $E_{\mathrm{f}}$ is the energy per fission (200 MeV).

For $\mathrm{PF}=10^{17}$ protons per second, which corresponds to $16.02 \mathrm{MW}$, the values of $G$ in the cases of $k_{\text {eff }}=0.98$ are given in Table II. These values vary in the range of 87 to 126 , depending on used isotope and the enrichment of the uranium, which are quite high values in terms of 


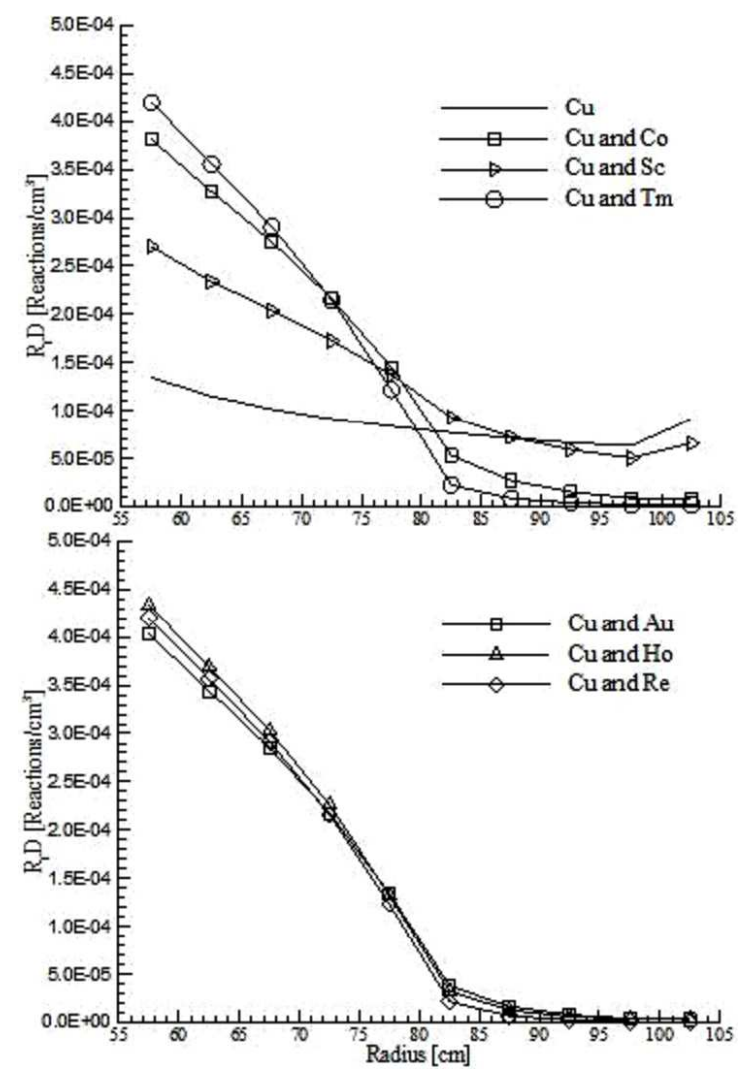

Fig. 2. Variations of fission density for all considered materials, as functions of the core radius.

energy multiplication. The energy of proton $\left(E_{\mathrm{p}}\right)$, which is inversely proportional to the value of $G$, is calculated as follows:

$$
E_{\mathrm{p}}=\frac{P_{\mathrm{th}}}{G} .
$$

TABLE II

Activity in the case of $k_{\text {eff }}=0.98$ for power of $1000 \mathrm{MW}$ at the end of one hour process.

\begin{tabular}{|c|c|c|c|c|c|}
\hline \multirow[b]{2}{*}{ Material } & \multirow[b]{2}{*}{$\begin{array}{l}\mathrm{FF} \\
{[\%]}\end{array}$} & \multirow[b]{2}{*}{$G$} & \multicolumn{3}{|c|}{ 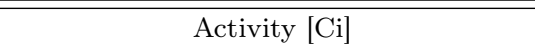 } \\
\hline & & & ${ }^{239} \mathrm{Pu}$ & ${ }^{64} \mathrm{Cu}$ & $\begin{array}{c}\text { Other } \\
\text { isotopes }\end{array}$ \\
\hline $\mathrm{Cu}$ & 8.2 & 87 & $5.270 \times 10^{8}$ & $1.243 \times 10^{7}$ & \\
\hline $\mathrm{Cu}$ and $\mathrm{Au}$ & 13 & 121 & $4.502 \times 10^{8}$ & $8.004 \times 10^{6}$ & ${ }^{198} \mathrm{Au}=2.307 \times 10^{6}$ \\
\hline $\mathrm{Cu}$ and $\mathrm{Co}$ & 12.45 & 123 & $4.645 \times 10^{8}$ & $7.875 \times 10^{6}$ & ${ }^{60} \mathrm{Co}=2.292 \times 10^{3}$ \\
\hline $\mathrm{Cu}$ and $\mathrm{Ho}$ & 13.4 & 126 & $4.287 \times 10^{8}$ & $7.844 \times 10^{6}$ & ${ }^{166} \mathrm{Ho}=5.204 \times 10^{6}$ \\
\hline $\mathrm{Cu}$ and $\mathrm{Re}$ & 13.5 & 118 & $4.305 \times 10^{8}$ & $8.051 \times 10^{6}$ & ${ }^{186} \mathrm{Re}=8.307 \times 0^{5}$ \\
\hline $\mathrm{Cu}$ and $\mathrm{Sc}$ & 10.58 & 123 & $5.025 \times 10^{8}$ & $6.553 \times 10^{6}$ & ${ }^{46} \mathrm{Sc}=5.871 \times 10^{4}$ \\
\hline $\mathrm{Cu}$ and $\mathrm{Tm}$ & 13.5 & 118 & $4.292 \times 10^{8}$ & $8.039 \times 10^{6}$ & ${ }^{170} \mathrm{Tm}=5.485 \times 10^{4}$ \\
\hline
\end{tabular}

\subsection{Breeding density}

New isotope production via $(n, \gamma)$ reactions is generally described as follows:

$$
\begin{aligned}
& { }^{238} \mathrm{U}(n, \gamma){ }^{239} \mathrm{U} \stackrel{\beta}{\longrightarrow}{ }^{239} \mathrm{~Np} \stackrel{\beta}{\longrightarrow}{ }^{239} \mathrm{Pu} \\
& { }^{A} \text { Isotope }(n, \gamma){ }^{A+1} \text { Isotope, }
\end{aligned}
$$

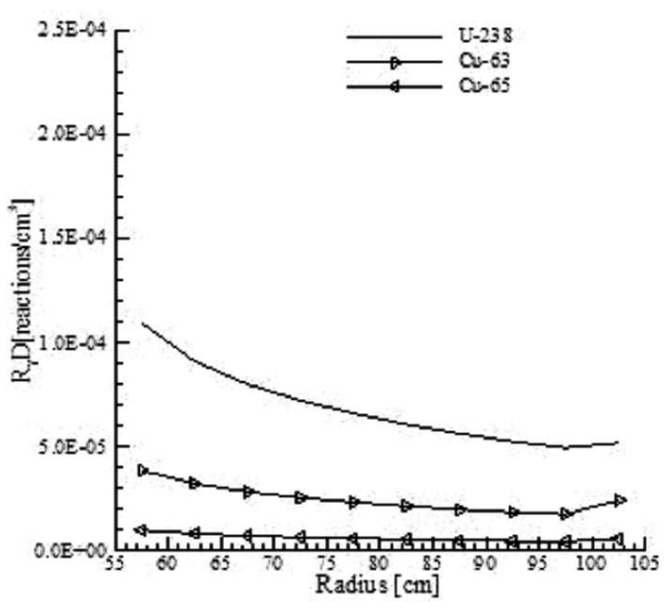

Fig. 3. Variations of breeding density in the case of UC and $\mathrm{Cu}$, as functions of the core radius.
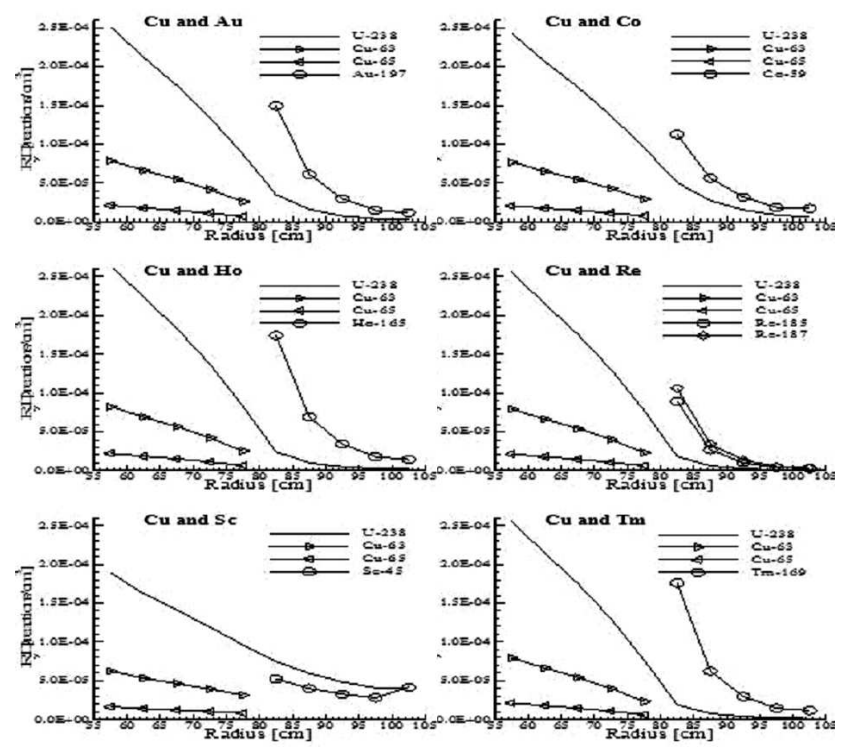

Fig. 4. Variations of breeding density in the case of UC and other materials, as functions of the core radius.

\section{Conclusions}

A conceptual cylindrical ADS is analyzed for radioisotope breeding and energy production. The main results obtained from this study are given briefly as follows:

- For productions of radioisotopes, the cases of copper-gold and copper-holmium are the best, 8.853 gram per hour and 8.265 gram per hour, respectively.

- For production of ${ }^{239} \mathrm{Pu}$, the case of copper and scandium is the best, 31.941 gram per hour.

- The energy gain can reach values up to 126 .

In conclusion, the investigated ADS has a good neutronic performance in terms of energy production and the breeding of radioisotope and fissile fuel. 


\section{Acknowledgments}

This study is supported by the Research Fund of Erciyes University, Project no. FYL-2015-6025.

\section{References}

[1] V.N. Starovoitova, L. Tchelidze, D.P. Wells, Appl. Radiat. Isotopes 85, 39 (2014).

[2] V.N. Richards, E. Mebrahtu, S.E. Lapi, Nucl. Med. Biol. 40, 939 (2013).

[3] W.D. Webster, G.T. Parks, D. Titov, P. Beasley, Nucl. Med. Biol. 41, e7 (2014).

[4] K. Abbas, S. Buono, N. Burgio, G. Cotogno, N. Gibson, L. Maciocco, G. Mercurio, A. Santagata, F. Simonelli, H. Tagziria, Nucl. Instrum. Methods A601, 223 (2009).

[5] T. Kin, Y. Nagai, N. Iwamoto, F. Minato, O. Iwamoto, Y. Hatsukawa, M. Segawa, H. Harada, C. Konno, K. Ochiai, K. Takakura, J. Phys. Soc. Jpn. 82, 034201 (2013).

[6] F. Tárkányi, S. Takács, A. Hermanne, F. Ditroí, B. Király, M. Baba, T. Ohtsuki, S.F. Kovalev, A.V. Ignatyuk, Appl. Radiat. Isotopes 67, 243 (2009).

[7] F. Tárkányi, A. Hermanne, S. Takács, I.F. Ditró, B. Király, S.F. Kovalev, A.V. Ignatyuk, J. Labelled Compd. Radiopharmaceuticals (Suppl. 50), S99 (2007).

[8] F. Tárkányi, A. Hermanne, S. Takács, I.F. Ditró, B. Király, S.F. Kovalev, A.V. Ignatyuk, Nucl. Instrum. Methods B266, 3346 (2008).
[9] F. Tárkányi, A. Hermanne, S. Takács, I.F. Ditró, B. Király, S.F. Kovalev, A.V. Ignatyuk, Nucl. Instrum. Methods B266, 3529 (2008).

[10] S.G. Lebedev, L.Y. Sosnin, A.N. Cheltsov, Nucl. Instrum. Methods in Phys. Res. A613, 477 (2010).

[11] O. Artun, H. Aytekin, Nucl. Instrum. Meth. in Phys. Res. B345, 1 (2015).

[12] F.M. Nortier, S.J. Mills, G.F. Steyn, Radiat. Isot. 46, 1377 (1995).

[13] M. Fassbender, W. Taylor, D. Vieira, M. Nortier, H. Bach, K. John, Appl. Radiat. Isotopes 70, 72 (2012).

[14] W. Courtney, K. Sowder, M. McGyver, N. Stevenson, D. Brown, Nucl. Instrum. Meth. Phys. Res. B261, 739 (2007)

[15] S. Okuducu, N. Aktı, E. Eser, Ann. Nucl. Energy 38, 1769 (2011).

[16] H. Yapıcı, G. Genç, N. Demir, Ann. Nucl. Energy 34, 374 (2007).

[17] H. Yapıcı, G. Genc, N. Demir, Ann. Nuclear Energy 35, 1264 (2008).

[18] D.B. Pelowitz, MCNPX, User's Manual, Version 2.6.0, LA-CP-07-1473, 2008.

[19] M.B. Chadwick, P.G. Young, S. Chiba, S.C. Frankle, G.M. Hale, H.G. Hughes, A.J. Koning, R.C. Little, R.E. MacFarlane, R.E. Prael, L.S. Waters, Nucl. Sci. Eng. 131, 293 (1999)

[20] H.W. Bertini, Phys. Rev. 188, 1711 (1969). 